\title{
Comparative addition of dexmedetomidine and fentanyl to intrathecal bupivacaine in orthopedic procedure in lower limbs
}

\author{
Poupak Rahimzadeh ${ }^{1}$, Seyed Hamid Reza Faiz ${ }^{2^{*}} \mathbb{D}$, Farnad Imani ${ }^{1}$, Pooya Derakhshan ${ }^{3}$ and Saeed Amniati ${ }^{3}$
}

\begin{abstract}
Background: Spinal block is a common procedure for lower limbs surgery. Fentanyl, a synthetic opioid and dexmedetomidine, a selective a2 agonist have been used as adjuvants in spinal anesthesia to prolong intraoperative and postoperative analgesia. The aim of current study is to compare the efficacy of dexmedetomidine and fentanyl added to intrathecal bupivacaine in orthopedic procedures in lower limbs.
\end{abstract}

Methods: In this randomized clinical trial, 90 patients undergoing elective lower limb surgeries were randomly allocated to three groups. Via intrathecal approach, the patients received $2.5 \mathrm{ml}$ hyperbaric bupivacaine $0.5 \%$ plus 5 micrograms dexmedetomidine (BD group), 25 micrograms fentanyl (BF group) or $0.5 \mathrm{ml}$ normal saline (BN group), respectively. Time to reach the complete motor block, the highest sensory level, regression from block, analgesic request and duration of the drug effect, hemodynamic changes and side effects were compared between the groups.

Results: There was no significant difference between the groups regrading time to reach complete motor block, but time to reach the highest sensory level was shorter in group BD than group BF ( $6.28 \pm 1.75$ vs. $7.17 \pm 1.45$, $p=0.03$ ). Group BD had significantly lower mean of NRS $6 \mathrm{~h}$ after operation ( $1.90 \pm 0.84$ vs. $6.16 \pm 1.44$ vs. $6.30 \pm 1.17$, $p<0.001)$ and longer duration to regress to Bromage 0 (331.60 \pm 73.96 vs. $185.56 \pm 35.87$ vs. $147.03 \pm 33.05$ min, $p<0.001$ ), to analgesic request (496.63 \pm 70.19 vs. $296.33 \pm 44.83$ vs. $221.83 \pm 22.26 \mathrm{~min}, p<0.001$ ), to regress two sensory levels ( $149.00 \pm 23.17$ vs. $88.90 \pm 12.85$ vs. $69.33 \pm 6.67 \mathrm{~min}, p<0.001)$ and to regress to $\mathrm{S} 1$ (560.53 \pm 81.86 vs. $329.83 \pm 44.10$ vs. $241.83 \pm 22.26 \mathrm{~min}, p<0.001)$. Serial changes in $\operatorname{SBP}(p=0.006)$, $\operatorname{DBP}(p=0.03)$ and $\operatorname{HR}(p=0.002)$ in group BF were significantly higher than the other two groups. The three groups had comparable side effects.

Conclusions: Using dexmedetomidine as an adjuvant to bupivacaine for spinal anesthesia in lower limb surgeries has longer duration of sensory and motor block and longer postoperative analgesia.

Trial registration: IRCT registration number: IRCT2017041010599N15, 24 May 2017.

Keywords: Lower limb surgery, Dexmedetomidine, Fentanyl, Intrathecal, Pain management

\section{Background}

Lower limb surgeries could be performed under local, neuroaxial and general anesthesia, but neuroaxial block is the preferred method. Spinal block has rapid onset, deep block, lower risk of infection and is cost effective. However, post-operative pain is an important problem as

\footnotetext{
* Correspondence: hrfaiz@hotmail.com

${ }^{2}$ Rasoul-e-Akram Clinical Research Development Center, Iran University of Medical Sciences, Tehran, Iran

Full list of author information is available at the end of the article
}

the used drugs have limited duration of effect; so the post-operative analgesic administration is necessary $[1,2]$.

Administrating the combinations of other classes of analgesics with local anesthetics has used to increase the duration and reduce side effects of analgesia [3]. Some drugs have been used as adjuvants in spinal anesthesia to prolong intraoperative and postoperative analgesia [1, 2] including opioids, $\alpha 2$ agonists, neostigmine, vasoconstrictors, etc. Clonidine and dexmedetomidine are two $\alpha 2$ agonists affecting via pre- and post-synaptic $\alpha 2$ receptors [4]. Dexmedetomidine has 
been widely used for anesthesia and analgesic purposes. This drug has sedative, anti-anxiety, analgesic, neuroprotective, and anesthetic-sparing effects [5]. Dexmedetomidine along with other drugs have been used to increase the duration of analgesia in subarachnoid, epidural and caudal blocks [6, 7].

Fentanyl is a synthetic opioid with central action, which is used widely for pain control. Intrathecal fentanyl is usually added to other local anesthetics to increase anesthesia and analgesia. It has improved spinal anesthesia and reduced the anesthetic drug related side effects including pruritus, nausea and vomiting [8].

Dexmedetomidine and fentanyl have been used as adjuvant to local anesthetics in different surgeries to provide superior analgesia and to improve the duration of the block [9-11]. One study on lower limbs surgery showed a better efficacy with dexmedetomidine [12].

In this study, we aim to compare the efficacy of dexmedetomidine and fentanyl added to intrathecal bupivacaine in orthopedic procedures in lower limbs in terms of block strength and time.

\section{Methods}

In this randomized double-blinded clinical trial, patients between 20 and 65 years old, American Society of Anesthesiologist (ASA) grade I and II of either gender undergoing elective lower limb surgeries at Rasoul-e-Akram Hospital in 2017 were recruited. If the patients were addict and very obese, had uncontrolled hypertension or diabetes mellitus, renal or hepatic failure, cardiac block or dysrythmia, coagulopathies, neurologic disorders, hypersensitivity to any of the study drugs and known contra indications to spinal anesthesia, they would be excluded. The study was reviewed and approved by the Iran University of Medical Science Ethics Committee and written informed consent was obtained from all subjects before inclusion in the study.

The study sample size was calculated by $n=$ $\frac{\left(s_{1}^{2}+s_{2}^{2}\right)\left(z_{1-\frac{\alpha}{2}}+z_{1-\beta}\right)^{2}}{\left(\bar{x}_{1}-\bar{x}_{2}\right)^{2}}$ using the results of Yektash et al.(2014) and through the following formula. Considering $\alpha=0.05$, power of $90 \%$ was calculated 29 per each group. Given

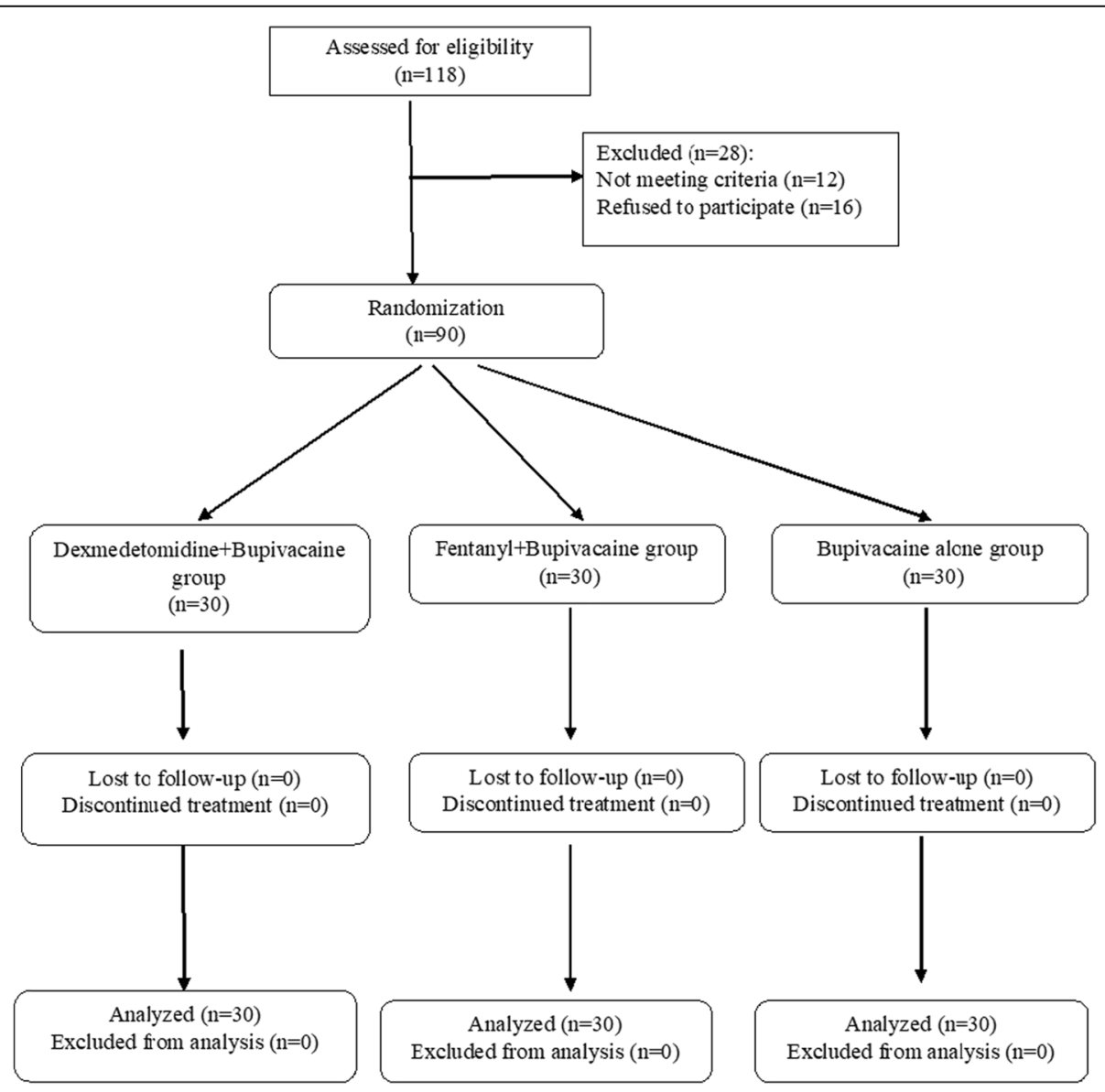

Fig. 1 Flowdiagram of study protocol 
Table 1 Baseline findings between groups

\begin{tabular}{lllll}
\hline & & $\begin{array}{l}\text { BN group } \\
(n=30)\end{array}$ & $\begin{array}{l}\text { BF group } \\
(n=30)\end{array}$ & $\begin{array}{l}\text { BD group } \\
(n=30)\end{array}$ \\
\hline Age (years) & & $39.43 \pm 14.82$ & $39.26 \pm 15.81$ & $42.20 \pm 15.32$ \\
Gender & Male & $20(66.7 \%)$ & $21(70 \%)$ & $19(63.3 \%)$ \\
& Female & $10(33.3 \%)$ & $9(30 \%)$ & $11(36.7 \%)$ \\
Weight $(\mathrm{kg})$ & & $69.90 \pm 13.45$ & $73.90 \pm 11.44$ & $72.40 \pm 11.68$ \\
Height $(\mathrm{cm})$ & $171.66 \pm 7.94$ & $174.06 \pm 8.26$ & $171.83 \pm 6.21$ & 0.7 \\
Body mass index $\left(\mathrm{kg} / \mathrm{m}^{2}\right)$ & $23.65 \pm 3.94$ & $24.30 \pm 2.79$ & $24.48 \pm 3.47$ & 0.39 \\
\hline
\end{tabular}

that " $\mathrm{g}$ " is the number of group, then the total sample size was 82 by using the following formula: $n^{\prime}=n * \sqrt{ }(g-1)$ for each group as there was possibility that some patients do not complete the study; $10 \%$ drop-out rate, we included 30 patients for each group $[13,14]$.

Using Block Randomization, according to sample size, the patients were enrolled into the study (Fig. 1).

The patients were randomly allocated to bupivacaine (Marcaine spinal 0.5\% heavy Astrazeneca, Cenexi, France) and normal saline $(\mathrm{BN})$, bupivacaine and dexmedetomidine (Precedex, Hospira co., USA) (BD) and bupivacaine and fentanyl (Caspian Darou, Rasht, Iran) (BF). The patients received $2.5 \mathrm{ml}$ intrathecal hyperbaric bupivacaine with $0.5 \mathrm{ml}$ normal saline (BN) or 5 micrograms dexmedetomidine (BD) or 25 micrograms fentanyl (BF). All medications were prepared in $3 \mathrm{ml}$ syringes. The patients and physician evaluating the outcome of the treatments were blinded to the group allocation.

All the patients were kept for $8 \mathrm{~h}$ fasting prior to surgery. Preloading completed with Ringer lactate solution (5 ml/kg body weight). Standard monitoring including noninvasive blood pressure (NIBP), ECG, heart rate and pulse oximetry performed. All patients received supplemental oxygen via mask $(5 \mathrm{l} / \mathrm{min})$. Under proper aseptic conditions, spinal anesthesia was given at the level of L4-L5 interspace in sitting position using a midline or paramedian approach by a 25G Quincke spinal needle. The anesthetic medication is injected at a rate of approximately $2 \mathrm{ml} / \mathrm{sec}$; and then all patients were made supine.
Blood pressure, heart rate and pulse oximetry were performed every minute in the first $10 \mathrm{~min}$ and then every five minutes for one hour. We recorded systolic and diastolic blood pressure and heart rate before regional anesthesia and in the 5, 10, 15, 30, 45 and $60 \mathrm{~min}$ after anesthesia. All data were recorded in a data sheet specified to each patient.

As we needed anesthetic effects, both sensory and motor status were assessed prior to the spinal injection, then every 2 min after injection until reaching the highest sensory level and Bromage scale reaching to Bromage 3. After surgery, assessment performed every $10 \mathrm{~min}$ until the time to regression of 2 sensory levels, then every $20 \mathrm{~min}$ until the regression time to the dermatome S1 and motor scale to Bromage 0.

The motor dermatome level was assessed according to the Bromage scale:

Bromage 0 (none): Free movement of legs and feet.

Bromage I (Partial): Just able to flex knees with free movement of feet.

Bromage II (Almost complete): Unable to flex knees, but with free movement of feet.

Bromage III (Complete): Unable to move legs or feet.

Severity of pain $6 \mathrm{~h}$ after surgery was measured by Numeric Rating Scale (NRS). The patients were asked to rate their pain from a scale of $0=$ no pain to $10=$ the worst possible pain. In case of any side effects it was recorded.

Hypotension was defined as decrease in systolic blood pressure (SBP) more than $30 \%$ of baseline or $\mathrm{SBP}<90 \mathrm{mmHg}$. If hypotension occurred, $10 \mathrm{mg}$

Table 2 Characteristics of block between three groups

\begin{tabular}{llll}
\hline & $\begin{array}{l}\text { BN group } \\
(n=30)\end{array}$ & $\begin{array}{l}\text { BF group } \\
(n=30)\end{array}$ & $\begin{array}{l}\text { BD group } \\
(n=30)\end{array}$ \\
\hline Time from injection to highest sensory level (min) & $6.45 \pm 1.67$ & $7.17 \pm 1.45$ & $6.28 \pm 1.75$ \\
Time of two segment regression from the highest sensory level (min) & $69.33 \pm 6.67$ & $88.90 \pm 12.85$ & $149.00 \pm 23.17$ \\
Time for sensory regression to S1 from highest sensory level (min) & $241.83 \pm 22.26$ & $329.83 \pm 44.10$ & $560.53 \pm 81.86$ \\
Onset to Bromage 3 (min) & $5.55 \pm 167$ & $5.05 \pm 1.81$ & $4.80 \pm 1.74$ \\
Regression to Bromage 0 (min) & $147.03 \pm 33.05$ & $185.56 \pm 35.87$ & $331.60 \pm 73.96$ \\
Time to rescue analgesia (min) & $221.83 \pm 22.26$ & $296.33 \pm 44.83$ & $496.63 \pm 70.19$ \\
NRS six hours after surgery & $6.30 \pm 1.17$ & $6.16 \pm 1.44$ & $1.90 \pm 0.84$ \\
\hline
\end{tabular}


Table 3 Highest dermatome level of sensory block

\begin{tabular}{llll}
\hline BN group & $\begin{array}{l}\text { BF group } \\
(n=30)\end{array}$ & $\begin{array}{l}\text { BD group } \\
(n=30)\end{array}$ \\
\hline T4 & 0 & $1(3.3 \%)$ & $3(10 \%)$ \\
T5 & $3(10 \%) 1$ & $7(23.3 \%)$ & $8(26.7 \%)$ \\
T6 & $12(40 \%)$ & $16(53.3 \%)$ & $12(40 \%)$ \\
T7 & $10(33.3 \%)$ & $3(10 \%)$ & $4(13.3 \%)$ \\
T8 & $5(16.7 \%)$ & $2(6.7 \%)$ & $3(6.7 \%)$ \\
\hline
\end{tabular}

ephedrine would be administered. Bradycardia was defined as heart rate (HR) below 50 pulses per minute and if occurred, $0.6 \mathrm{mg}$ atropine would be administered.

\section{Statistical analysis}

All data were analyzed using SPSS24 (version 24; SPSS Inc., Chicago, IL). The results are expressed as Mean \pm standard deviation or percentage. The nominal categorical data between study groups were compared by using the chi-squared test or Fisher's exact test as appropriate. One-way ANOVA and repeated measure of ANOVA were used to evaluate the changes in the variables during the study period. $p$-values of less than 0.05 were considered statistically significant.

\section{Results}

Ninety patients were randomly allocated to three groups of 30 patients. There was no significant difference between the groups in baseline findings (Table 1).
Characteristics of block between the three groups are demonstrated in Table 2. There was significant differences between $\mathrm{BD}$ with $\mathrm{BF}$ and $\mathrm{BN}$ groups in regression to Bromage $0(p<0.001)$, two segmental regression $(p<0.001)$, sensory regression to S1 $(p<0.001)$, time to rescue analgesia $(p<0.001)$ and NRS $6 \mathrm{~h}$ after surgery $(p<0.001)$ and between $\mathrm{BF}$ and $\mathrm{BN}$ in regression to Bromage $0(p=0.004)$, sensory regression to S1 $(p<0.001)$, time to rescue analgesia $(p<0.001)$, two segmental regression $(p<0.001)$, and between $\mathrm{BD}$ and $\mathrm{BF}$ in the highest sensory level $(p=0.03)$, but there was no significantly difference between groups in onset of Bromage $3(p>0.05)$.

In all three groups, the highest sensory block occurred in T6 dermatome (Table 3). T5 dermatome was the second highest in $\mathrm{BD}$ and $\mathrm{BF}$ groups, but $\mathrm{T} 7$ dermatome was the second highest block in BN group.

Figures 2 and 3 demonstrate Error bars of systolic and diastolic blood pressure and heart rate changes between groups before spinal anesthesia till $60 \mathrm{~min}$ after in each and between groups. Serial changes in SBP, DBP and HR were significant in each group $(p<0.001)$; these changes and reduction in SBP $(p=0.006), \mathrm{DBP}(p=0.03)$ and HR $(p=0.002)$ in $\mathrm{BF}$ group were significantly higher than $\mathrm{BD}$ and $\mathrm{BN}$ groups.

Nausea, vomiting and chilling were higher in $\mathrm{BN}$ group and hypotension and bradycardia were higher in $\mathrm{BF}$ group, but there were no significant differences between three groups regarding the treatment side effects (Table 4).

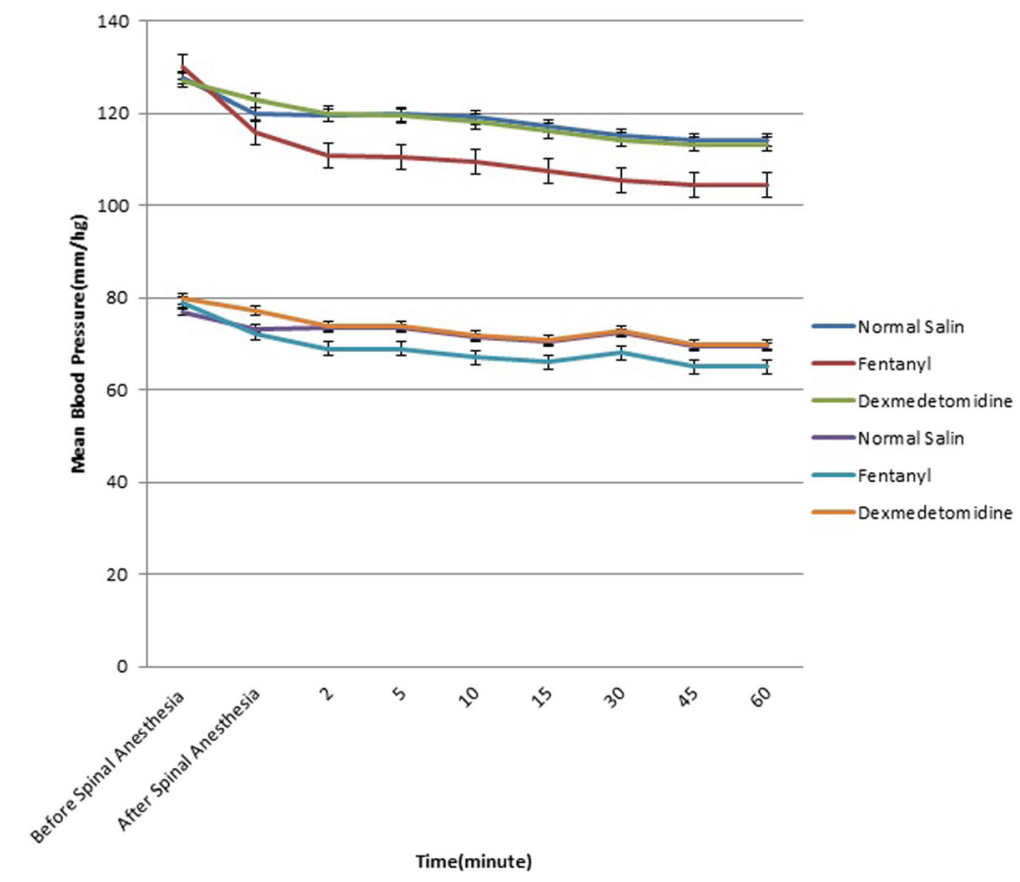

Fig. 2 Error Bars of Systolic and diastolic blood pressure changes between groups before spinal anesthesia till 60 min after in between groups 


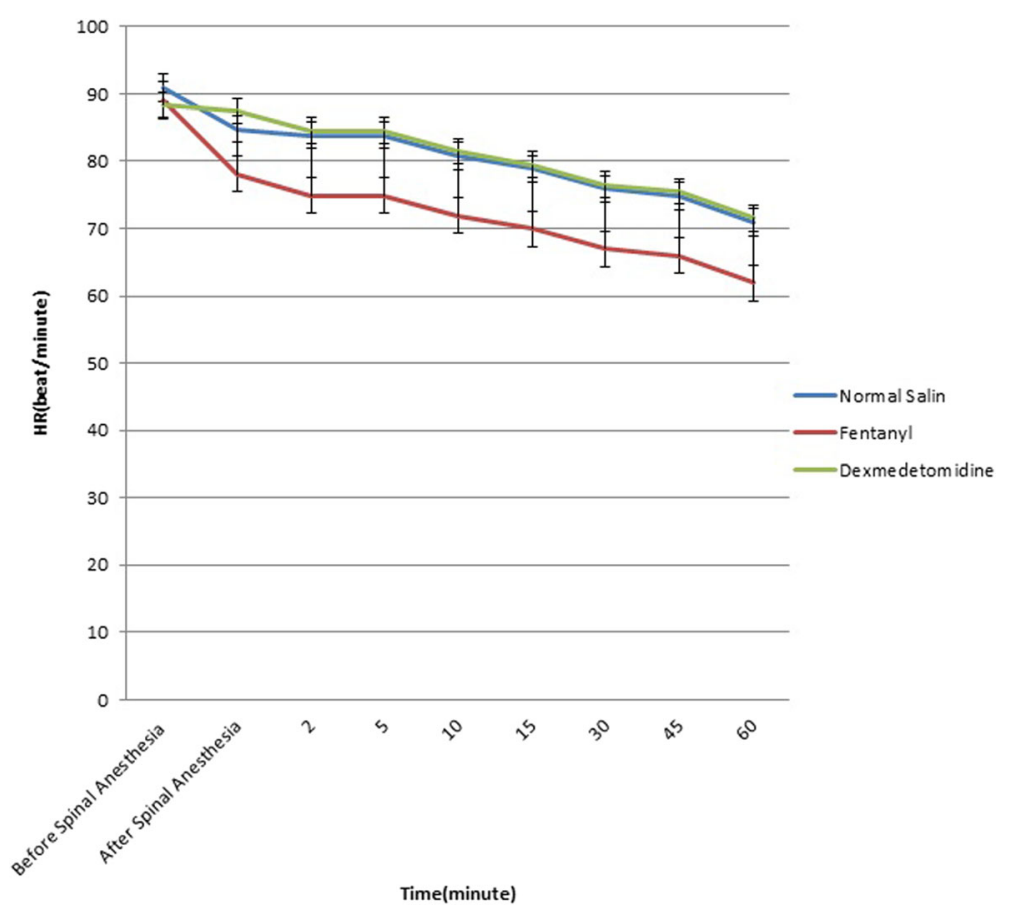

Fig. 3 Error Bar of Heart rate changes between groups before spinal anesthesia till 60 min after in between groups

\section{Discussion}

In this study, we evaluated the efficacy of three spinal anesthesia methods, bupivacaine alone or with dexmedetomidine or fentanyl in lower limb orthopedic surgeries. Although there was no significant difference between groups in time to onset of Bromage 3 and complete motor block, BD group had lower time to reach the highest sensory level than BF group, with no difference with $\mathrm{BN}$ group but it was not statistically significant. $(P$-value $=0.08)$.

Similarly, Mahendru et al. [12] found no significant difference in onset of motor block between dexmedetomidine and fentanyl groups. While Yektas [13] and Ravipati [15] reported faster onset of motor block for dexmedetomidine compared to fentanyl. Other studies have also mentioned lower time to reach the highest sensory level in dexmedetomidine compared to fentanyl [12-19].

Table 4 Side effects between groups

\begin{tabular}{llll}
\hline & BN group $(n=30)$ & BF group $(n=30)$ & BD group $(n=30)$ \\
\hline Nausea & $2(6.7 \%)$ & $1(3.3 \%)$ & $1(3.3 \%)$ \\
Vomiting & $2(6.7 \%)$ & 0 & 0 \\
Chilling & $2(6.7 \%)$ & $2(6.7 \%)$ & $1(3.3 \%)$ \\
Pruritus & 0 & $2(6.7 \%)$ & 0 \\
Hypotension & 0 & $3(10 \%)$ & $1(3.3 \%)$ \\
Bradycardia & 0 & $3(10 \%)$ & $1(3.3 \%)$ \\
\hline
\end{tabular}

The mechanism of how dexmedetomidine prolongs sensory and motor blockade is not known. Dexmedetomidine is a highly-selective $\alpha 2$-adrenergic receptor agonist that causes analgesia by suppression the release of $\mathrm{C}$ fiber transmitters and hyperpolarization of post-synaptic neurons [13].

In our study, the highest sensory level in $\mathrm{BD}$ and $\mathrm{BF}$ group were $\mathrm{T} 6$ and $\mathrm{T} 5$ while in $\mathrm{BN}$ group was $\mathrm{T} 6$ and T7 dermatomes. One study reported the highest sensory level at T5 dermatome [15] and Mahendru [12] reported in T6 dermatome. Other study reported the highest sensory level at $\mathrm{T} 5$ dermatome in dexmedetomidine and T6 in fentanyl group [20].

None of the patients requested analgesic during the surgery. Bromage 3 occurred in all patients before operation. Complete regression of motor block (Bromage 0) was reached in all patients and with the highest duration in $\mathrm{BD}$ group. Moreover, time to regression to S1 sensory level and regression of two sensory levels in BD group was significantly longer than the other groups. These patients also experienced lower pain intensity six hours after surgery indicative of the highest postoperative analgesia duration in $\mathrm{BD}$ group.

Reduced need for analgesics in the post-operation period, more stable hemodynamics, longer duration of sensory and motor block for dexmedetomidine have been reported in previous studies comparing this drug with other drugs such as clonidine, fentanyl and sufentanil $[16,19,21-24]$. In orthopedic surgeries of lower 
limb, better results have also been reported for dexmedetomidine compared to fentanyl $[12,13]$.

Hemodynamic changes is common in anesthesia medications. We observed that changes in SBP, DBP and HR in $\mathrm{BF}$ was higher than $\mathrm{BD}$ and $\mathrm{BN}$ groups, with no difference between $\mathrm{BD}$ and $\mathrm{BN}$ patients. The highest decline occurred 5 min after spinal injection and was rather stable afterwards. Unlike our findings, other studies did not report any significant difference between fentanyl and dexmedetomidine regarding hemodynamic status [12, 13, 15-18]. Decline in HR and blood pressure are common effects of opioids. The difference in hemodynamic findings could be due to the response of each individual to the drug, demographic profile, volume of IT injectate and volume of diluent used.

Side effects may occur by using any anesthesia medications. The best medication is the one with the highest efficacy and lowest side effects. We observed no significant difference in the rate of hypotension, bradycardia, nausea and vomiting and chilling between groups. Previous studies have reported different rate of side effects. Similar to our findings, Ravipati [15] observed pruritus only in fentanyl group while nausea and vomiting was more common in dexmedetomidine, with no significant difference between groups. There is also only one study reporting increase in hemodynamic side effects, bradycardia and hypotension, in dexmedetomidine [24].

Another important side effect of anesthesia medications is respiratory system suppression. However, we observed no respiratory suppression. First, fentanyl compared to other opioids is less likely to cause respiratory suppression. Second, this complication is not common in dexmedetomidine.

In order to reach better efficacy, we can increase the dose of the used dexmedetomidine. Gupta [19] reported that increasing the dose of dexmedetomidine from $2.5 \mu \mathrm{g}$ to $10 \mu \mathrm{g}$ would show better and longer sensory and motor block, with longer duration of anesthesia and comparable hemodynamic and side effects profile.

\section{Conclusion}

In conclusion, using dexmedetomidine as an adjuvant to bupivacaine for intrathecal analgesia in lower limb surgeries has longer duration of sensory and motor block, longer postoperative analgesia with low side effects. All three treatments had lower side effects with no difference between groups.

\section{Abbreviations}

ANOVA: Analysis of variance; ASA: American Society of Anesthesiologist; BD: Bupivacaine + Dexmedetomidine; BF: Bupivacaine + fentanyl: BN: Bupivacaine + normal saline; ECG: Electrocardiogram; HR: Heart rate; NIBP: Noninvasive blood pressure; NRS: Numeric Rating Scale; SBP: Systolic blood pressure; SPSS: Statistical Package for the Social Sciences

\section{Acknowledgments}

The authors would like to thank Rasoul-e-Akram Clinical Research Development Center, Iran University of Medical Sciences for their technical support.

\section{Availability of data and materials}

The datasets used and/or analyzed during the current study are available from the corresponding author upon a reasonable request.

\section{Authors' contributions}

PR and HRF were responsible for the conception and design of the study. $\mathrm{PR}, \mathrm{HRF}, \mathrm{Fl}$ and SA were responsible for acquisition and analysis of data. Furthermore, SA was in charge of statistical analysis. PD and SA drafted the manuscript and the final approved version. All authors read and approved the final manuscript.

Ethics approval and consent to participate

The Ethical Committee of Iran University of Medical Sciences approved the study and written informed consents were obtained from all participants.

\section{Competing interests}

The authors declare that they have no competing interests.

\section{Publisher's Note}

Springer Nature remains neutral with regard to jurisdictional claims in published maps and institutional affiliations.

\section{Author details}

${ }^{1}$ Pain Research Center, Iran University of Medical Sciences, Tehran, Iran. ${ }^{2}$ Rasoul-e-Akram Clinical Research Development Center, Iran University of Medical Sciences, Tehran, Iran. ${ }^{3}$ Rasoul-e-Akram Medical Complex, Iran University of Medical Sciences, Tehran, Iran.

Received: 29 December 2017 Accepted: 25 May 2018 Published online: 06 June 2018

\section{References}

1. Elia N, Culebras X, Mazza C, Schiffer E, Tramèr MR. Clonidine as an adjuvant to intrathecal local anesthetics for surgery: systematic review of randomized trials. Reg Anesth Pain Med. 2008;33(2):159-67.

2. Boussofara M, Carlès M, Raucoules-Aimé M, Sellam MR, Horn JL. Effects of intrathecal midazolam on postoperative analgesia when added to a bupivacaine-clonidine mixture. Reg Anesth Pain Med. 2006;31(6):501-5.

3. Faiz SH, Rahimzadeh P, Sakhaei M, Imani F, Derakhshan P. Anesthetic effects of adding intrathecal neostigmine or magnesium sulphate to bupivacaine in patients under lower extremities surgeries. J Res Med Sci. 2012:17(10):918-22.

4. Shah A, Patel I, Gandhi R. Haemodynamic effects of intrathecal dexmedetomidine added to ropivacaine intraoperatively and for postoperative analgesia. Int J Basic Clin Pharmacol. 2013;2(1):26-9.

5. Panzer O, Moitra V, Sladen RN. Pharmacology of sedative-analgesic agents: Dexmedetomidine, remifentanil, ketamine, volatile anesthetics, and the role of peripheral mu antagonists. Crit Care Clin. 2009;25(3):451-69. vii

6. Bekker A, Sturaitis M, Bloom M, Moric M, Golfinos J, Parker E, Babu R, Pitti A. The effect of dexmedetomidine on preoperative hemodynamics in patients undergoing craniotomy. Anesth Analg. 2008;107(4):1340-7.

7. Sudheesh $\mathrm{K}$, Harsoor S. Dexmedetomidine in anaesthesia practice: a wonder drug? Indian J Anaesth. 2011:55(4):323-4.

8. Liu SS, McDonald SB. Current issues in spinal anesthesia. Anesthesiology. 2001:94(5):888-906.

9. Mohamed T, Susheela I, Balakrishnan BP, Kaniyil S. Dexmedetomidine as adjuvant to lower doses of intrathecal bupivacaine for lower limb orthopedic surgeries. Anesth Essays Res. 2017;11(3):681-5.

10. Saadalla AET, Khalifa OYA. Influence of Addition of Dexmedetomidine or Fentanyl to Bupivacaine Lumber Spinal Subarachnoid Anesthesia for Inguinal Hernioplasty. Anesth Essays Res. 2017;11(3):554-7.

11. Faroog N, Singh RB, Sarkar A, Rasheed MA, Choubey S. To evaluate the efficacy of fentanyl and Dexmedetomidine as adjuvant to Ropivacaine in brachial plexus block: a double-blind, prospective. Randomized Study Anesth Essays Res. 2017;11(3):730-9.

12. Mahendru V, Tewari A, Katyal S, Grewal A, Singh MR, Katyal R. A comparison of intrathecal dexmedetomidine, clonidine, and fentanyl as adjuvants to 
hyperbaric bupivacaine for lower limb surgery: a double blind controlled study. J Anaesthesiol Clin Pharmacol. 2013;29(4):496-502.

13. Yektas A, Belli E. The effects of $2 \mu \mathrm{g}$ and $4 \mu \mathrm{g}$ doses of dexmedetomidine in combination with intrathecal hyperbaric bupivacaine on spinal anesthesia and its postoperative analgesic characteristics. Pain Res Manag. 2014;19(2):75-81.

14. Machin D, Campbell MJ, Tan S-B, Tan S-H. Sample size tables for clinical studies: John Wiley \& Sons; 2011.

15. Ravipati P, Isaac GA, Reddy PN, Krishna L, Supritha T. A comparative study between intrathecal isobaric Ropivacaine $0.75 \%$ plus Dexmedetomidine and isobaric Ropivacaine $0.75 \%$ plus fentanyl for lower limb surgeries. Anesth Essays Res. 2017;11(3):621-6.

16. Kanazi GE, Aouad MT, Jabbour-Khoury SI, Al Jazzar MD, Alameddine MM, Al-Yaman R, Bulbul M, Baraka AS. Effect of low-dose dexmedetomidine or clonidine on the characteristics of bupivacaine spinal block. Acta Anaesthesiol Scand. 2006;50(2):222-7.

17. Niu XY, Ding XB, Guo T, Chen MH, Fu SK, Li Q. Effects of intravenous and intrathecal Dexmedetomidine in spinal anesthesia: a meta-analysis. CNS Neurosci Ther. 2013;19(11):897-904.

18. Khan AL, Singh RB, Tripathi RK, Choubey S. A comparative study between intrathecal dexmedetomidine and fentanyl as adjuvant to intrathecal bupivacaine in lower abdominal surgeries: a randomized trial. Anesth Essays Res. 2015;9(2):139-48.

19. Gupta M, Gupta P, Singh DK. Effect of 3 different doses of intrathecal Dexmedetomidine $(2.5 \mu \mathrm{g}, 5 \mu \mathrm{g}$, and $10 \mu \mathrm{g})$ on subarachnoid block characteristics: a prospective randomized double blind dose-response trial. Pain Physician. 2016;19(3):E411-20.

20. Gupta R, Verma R, Bogra R, Kohli M, Raman R, Kushwaha JK. A comparative study of intrathecal dexmedetomidine and fentanyl as adjuvant to bupivacaine. J Anaesthesiol Clin Pharmacol. 2011;27(3):339-43.

21. Post C, Gordh T Jr, Minor BG, Archer T, Freedman J. Antinociceptive effects and spinal cord tissue concentrations after intrathecal injection of guanfacine or clonidine into rats. Anesth Analg. 1987;66(4):317-24.

22. Al Ghanem SM, Massad IM, Al-Mustafa MM, Al-Zaben KR, Qudaisat IY, Qatawneh AM, et al. Effect of adding dexmedetomidine versus fentanyl to intrathecal bupivacaine on spinal block characteristics in gynecological procedures: a double blind controlled study. Am J Appl Sci. 2009;6(5):882-7.

23. Al-Mustafa MM, Abu-Halaweh SA, Aloweidi AS, Murshidi MM, Ammari BA, Awwad ZM, Al-Edwan GM, Ramsay MA. Effect of dexmedetomidine added to spinal bupivacaine for urological procedures. Saudi Med J. 2009;30(3):365-70

24. Ibrahim FA. A comparative study of adding intrathecal dexmedetomidine versus sufentanil to heavy bupivacaine for postoperative analgesia in patients undergoing inguinal hernia repair. Benha M J. 2009;26(3):207-17.

\section{Ready to submit your research? Choose BMC and benefit from:}

- fast, convenient online submission

- thorough peer review by experienced researchers in your field

- rapid publication on acceptance

- support for research data, including large and complex data types

- gold Open Access which fosters wider collaboration and increased citations

- maximum visibility for your research: over $100 \mathrm{M}$ website views per year

At BMC, research is always in progress.

Learn more biomedcentral.com/submissions 